\title{
BIOSYNTHESIS OF $\triangle$-AMINOLEVULINATE IN GREENING BARLEY LEAVES III: THE FORMATION OF $\triangle$-AMINOLEVULINATE IN tigrina MUTANTS OF BARLEY
}

\author{
by \\ SIMON P. GOUGH and C. GAMINI KANNANGARA \\ Department of Physiology, Carlsberg Laboratory, \\ Gamle Carlsberg Vej 10. DK-2500 Copenhagen Valby
}

Keywords: Enzyme regulation, light, heme, chloroplast, etioplast

The tigrina mutants tig- $d^{22}$, tig- $b^{23}$ and tig-o $0^{34}$ form increased amounts of protochlorophyllide in the dark relative to the wild type. Levulinate, the inhibitor of $\delta$-aminolevulinate dehydratase was used to show that the high protochlorophyllide levels are due to rates of $\delta$-aminolevulinate formation which are 1.3 to 6 -fold higher than in the wild type. Bleached/necrotic bands in the tigrina-phenotype plants were due to photobleaching caused by a pigment accumulated during the dark but not during a light period in the part of the leaf where extension growth occurs.

Light inhibited $\delta$-aminolevulinate accumulation in the presence of levulinate in dark grown tig-d $d^{l} 2$ and $t i g-b^{2}-3$. Glutamate- $1-14 \mathrm{C}$ was incorporated more efficiently than glycine-2-14 $\mathrm{C}$ by dark grown leaves of $t i g-d^{I 2}$ and $t i g$ $b^{23}$ into $\delta$-aminolevulinate. It is concluded that these leaves formed $\delta$-aminolevulinate by the 5 -carbon pathway with the $\delta$-aminolevulinate synthesising enzyme. Etioplasts isolated from $t i g-d^{I} 2$ incorporated glutamate- $1-14 \mathrm{C}$ and $\alpha$-ketoglutarate- $1-{ }^{14} \mathrm{C}$ into $\delta$-aminolevulinate at rates 2 to 3 times that of the wild type. In the dark unregulated $\delta$-aminolevulinate formation in tig-d $d^{2}$ and basal $\delta$-aminolevulinate formation in the wild type was maintained by protein synthesis on cytoplasmic ribosomes. In tig-d/2 $\delta$-aminolevulinate formation was also somewhat dependent on protein synthesis on $70 \mathrm{~S}$ ribosomes.

Heme and protoporphyrin at $5 \mu \mathrm{M}$ inhibited the partially purified $\delta$-aminolevulinate synthesising enzyme from the wild type by $80 \%$ and $27 \%$ respectively. In disrupted etioplast preparations light stimulated $\delta$ aminolevulinate synthesising activity. It is suggested that light activates the $\delta$-aminolevulinate synthesising enzyme formed in dark-grown barley seedlings through a photosensitive effector and that heme is a feedback inhibitor. 


\section{INTRODUCTION}

In barley chlorophyll synthesis in the light and protochlorophyllide formation in the dark are regulated at the stage of $\delta$-aminolevulinate formation. This conclusion is based on the observations that inhibition of chlorophyll synthesis by cycloheximide is circumvented by feeding $\delta$-aminolevulinate (15) and that the small amount of protochlorophyllide accumulated in the dark is greatly increased upon feeding with $\delta$ aminolevulinate (9).

In a previous paper (8) the light stimulated accumulation of $\delta$-aminolevulinate in the wild type was studied and it was concluded that light stimulated the accumulation of $\delta$-aminolevulinate by removing a feedback inhibitor as well as by inducing protein synthesis. It has further been shown that the synthesis of the $\delta$-aminolevulinate synthesising enzyme is light inducible (14). Mutants with lesions affecting the chlorophyll pathway are particularly useful in a study of the induction and regulation of $\delta$-aminolevulinate formation. The genetic lesions can be considered as specific internal probes for the pathway. The tigrina mutants at the loci tig-b, tig-d, tig-o and tig- $n$ have genetic lesions affecting the control of chlorophyll biosynthesis $(5,11,16,21)$. As a result they accumulate two to fifteen fold more protochlorophyllide than the wild type in the dark. Formation of $\delta$-aminolevulinate in these tigrina mutants was investigated in order to understand how chlorophyll biosynthesis is regulated.

\section{MATERIALS AND METHODS}

\subsection{Plant material}

The wild type barley referred to in this paper is Hordeum vulgare L.cv. Svalöf's Bonus unless otherwise stated. The following mutant material was used: $t i g-d^{12}, t i g-b^{23}$ and $t i g-o^{34}$. The genetic background of these mendelian gene mutants is Bonus (20). The mutants tig- $d^{12}$ and tig-o $0^{34}$ are the only known mutant alleles in these two genes. Of the four alleles known at the tig- $b$ locus the mutant $t i g-b^{23}$ has the most extreme phenotype and was therefore chosen for these studies. In general mutant material is maintained through heterozygotes, the seeds obtained from the selfed heterozygotes segregate to give homozygous mutants. The etiolated tigrina mutants are easily recognised as they are generally greener than the dark grown wild type due to an increased level of protochlorophyllide. The lightsensitive mutant tig- $d^{I 2}$ is also available as homozygous seed stock.

\subsubsection{Identification of etiolated mutant material}

Seeds were planted in a regular pattern in trays of moist vermiculite. Dark grown tigrina mutants were identified by removing apical one $\mathrm{cm}$ segments of the leaves and arranging them on a grid pattern in a moist chamber to correspond with the positions of the plants growing in the dark. The segments were then placed in light. The green tips of the homozygous tigrina mutants were immediately identified and after illumination overnight the seedlings heterozygous for $t i g-d^{I / 2}$ were revealed by the inability of their tips to green. The etiolated homozygous and heterozygous mutant leaves were harvested individually in dim green light after their position on the tray had been established by the location of mutant tips on the grid. In some experiments the tigrina mutants were identified at the end of the treatment by the following procedure: the shoots were cooled on ice to prevent changes in $\delta$-aminolevulinate levels and sorted in dim white light where the greener tigrina mutants could be seen.

\subsection{Radioactive chemicals}

L-glutamate-U-14 $\mathrm{C}$ (285 $\left.\mathrm{mCi} \cdot \mathrm{mmole}^{-1}\right)$, glycine- $2-{ }^{14} \mathrm{C}(54 \mathrm{mCi} \cdot \mathrm{mmole}-1)$, succinate $-2,3-{ }^{14} \mathrm{C}$ (50 mCi.mmole-1), L-glutamate- $1-{ }^{-19} \mathrm{C} \quad(50$ $\mathrm{mCi} \cdot \mathrm{mmole}^{-1)}, \quad \delta$-aminolevulinate-4- ${ }^{14} \mathrm{C} \quad(58$ $\left.\mathrm{mCi} \cdot \mathrm{mmole}^{-1}\right)$ and $\delta$-aminolevulinate-G- ${ }^{3} \mathrm{H}(3.7$ Ci.mmole $\left.{ }^{-1}\right)$ were obtained from the Radiochemical Centre, Amersham. $\alpha$-ketoglutarate- $1-{ }^{14} \mathrm{C}$ (49 $\mathrm{mCi} \cdot \mathrm{mmole}^{-1}$ ) was obtained from New England Nuclear.

\subsection{Growth of plants}

Seeds were germinated and grown in complete darkness in vermiculite watered with a mineral salt solution (8) unless otherwise stated. The seedlings were handled under dim green light. Seedling were grown either at $25 \pm 2{ }^{\circ} \mathrm{C}$ in closed cabinets in a dark room (8) or at 
$21 \pm 1.5^{\circ} \mathrm{C}$ in a dark room in which the relative humidity was controlled to around $70 \%$ (14).

\subsection{Light}

Fluorescent room lighting measured at $25 \mathrm{ft}$. candles was used for illumination of dark grown seedlings.

\subsection{Levulinate feeding and levulinate infiltration of shoots}

Unless otherwise stated the procedure previously described $(8)$ have been used.

\subsection{Plastid isolation}

Plastids were isolated from greening barley leaves or dark grown leaves as described in (14) with the following modifications. All operations with dark grown material were carried out under dim green light. Leaves were homogenised in a medium containing $0.6 \mathrm{~m}$-glycerol, $0.1 \mathrm{~m}$ Tricine, $1 \mathrm{~mm}-\mathrm{MgCl}_{2}$, and with the $\mathrm{pH}$ adjusted to 7.9 with $\mathrm{NaOH}$. Additional variations in the composition of the media are given in the table and figure legends.

\subsection{Partial purification of the $\delta$-aminolevulinate synthesising enzyme}

Plastids isolated from greening leaves were used for enzyme purification. These plastids were disrupted with a French Pressure cell at an internal cell pressure of 4,000 psi and ultracentrifuged for $15 \mathrm{~min}$ at $226,000 \mathrm{~g}$ and at 0 to $4{ }^{\circ} \mathrm{C}$ in a Beckman L5/75 ultracentrifuge to remove the membranes. The $\delta$-aminolevulinate synthesising activity in the supernatant was further purified by gel filtration using a Bio-gel A 0.5 column $(5 \times 36 \mathrm{~cm})$. The column was eluted with $0.3 \mathrm{M}$-glycerol, $0.1 \mathrm{~m}$-Tricine- $\mathrm{NaOH}$ $\mathrm{pH} 7.9,1 \mathrm{~mm}-\mathrm{MgCl}_{2}, 1 \mathrm{~mm}$-dithiothreitol and $0.5 \mathrm{~mm}$-ATP. The fractions were collected from the column and aliquots were assayed for $\delta$ aminolevulinate synthesising enzyme activity. The active fractions were pooled and concentrated by pressure dialysis.

\subsection{Assay for the $\delta$-aminolevulinate synthesising enzyme}

\subsubsection{Assay with etioplasts}

The ability of etioplasts to form $\delta$-aminolevulinate was measured by incubation of etioplasts in two ml of medium containing $0.3 \mathrm{M}$-glycerol, 0.1 m-Tricine- $\mathrm{NaOH}$ pH 7.9, 1 mm-dithiothreitol, I mM- $\mathrm{MgCl}_{2}, 25 \mathrm{~mm}$-Na-levulinate, $0.5 \mathrm{~mm}$ ATP, 0.5 mm-coenzyme $\mathrm{A}$ and $2.5 \mu \mathrm{Ci}$ of substrate. The incubations were for $15 \mathrm{~min}$ at $22^{\circ} \mathrm{C}$ in the dark.

\subsubsection{Assay with disrupted plastids}

$\delta$-Aminolevulinate synthesising activity was assayed with disrupted plastios immediately after disruption in two $\mathrm{ml}$ of medium containing the following cofactors and substrate: $0.5 \mathrm{~mm}$-ATP, I mM-NADPH, $26 \mathrm{~mm}-\mathrm{MgCl}_{2}$ and $2.5 \mu \mathrm{Ci}$ of $\mathrm{L}-$ glutamate-U. ${ }^{14} \mathrm{C}$. Incubations were carried out at $27^{\circ} \mathrm{C}$ for $15 \mathrm{~min}$ either in the light or in the dark (tubes wrapped in aluminium foil).

\subsubsection{Assay with partially purified enzyme}

The incubation mixture contained in one $\mathrm{ml}$, $3.6 \mathrm{mg}$ protein, $0.3 \mathrm{~m}$-glycerol, $0.1 \mathrm{~m}$-Tricine$\mathrm{NaOH}$ pH 7.9, 1 mm-dithiothreitol, $20 \mathrm{~mm}-$ $\mathrm{MgCl}_{2}, 1 \mathrm{~mm}$-ATP, $0.3 \mathrm{~mm}-\mathrm{NADPH}$ and 1.25 $\mu \mathrm{Ci}$ of $\mathrm{L}$-glutamate-U- ${ }^{4} \mathrm{C}$. The incubations were carried out for 15 minutes at $22^{\circ} \mathrm{C}$ in the dark.

\subsection{Measurement of protochlorophyllide content in preparations of disrupted etioplasts and photoconversion of protochlorophyllide}

Spectra of disrupted etioplast preparations were taken before and after a $15 \mathrm{~min}$ period in room light using an Aminco DW 2A spectrophotometer. The percent photoconversion and the true heights of the absorption peaks of photoinactive and active protochlorophyllide were determined as in (18). The amounts of protochlorophyllide were then calculated from these heights using a mmolar extinction coefficient of 3.4 at $628 \mathrm{~nm}$, a value determined in $80 \%$ acetone (6). 


\subsection{Determination of green pigments}

Protochlorophyllide and chlorophyll content was determined as given in (8) unless otherwise stated. The pigments determined in etiolated seedlings that were exposed to dim white light are underestimated because chlorophyll could not be extracted completely immediately after photoconversion (8) and because of the instability of chlorophyllide to light at low temperature (1).

\subsection{The determination of $\delta$-aminolevulinate- ${ }^{14} \mathrm{C}$ and \\ $\delta$-aminolevulinate accumulated in levulinate treated shoots}

$\delta$-Aminolevulinate formed in levulinate treated leaves was determined either without purification as described in (8) or after purification as described in (7) with the following modifications.
Shoots were ground in liquid nitrogen and the resulting powder was mixed with $5 \%$ perchloric acid. In order to determine the recovery of $\delta$ aminolevulinate in each analysis ${ }^{3} \mathrm{H}$ or ${ }^{14} \mathrm{C}$ labelled $\delta$-aminolevulinate as appropriate were added to the perchloric acid. The leaf homogenate was filtered, and adjusted to $\mathrm{pH} 1.6$ with $\mathrm{KOH}$. The precipitate of $\mathrm{KClO}_{4}$ was removed by centrifugation. The $\delta$-aminolevulinate was then purified and determined as described in (7) which involves the following steps: cation exchange chromatography, formation of the ethyl acetoacetate pyrrole, washing the aqueous solution of pyrrole with chloroform at $\mathrm{pH} 7.2$, extraction of the pyrrole into ether at $\mathrm{pH} 4.5$, evaporation of ether and subsequent determination of the pyrrole with modified Ehrlich reagent. In some cases as indicated chromatography of the $\delta$ aminolevulinate pyrrole was carried out before the final determination with Ehrlich reagent.

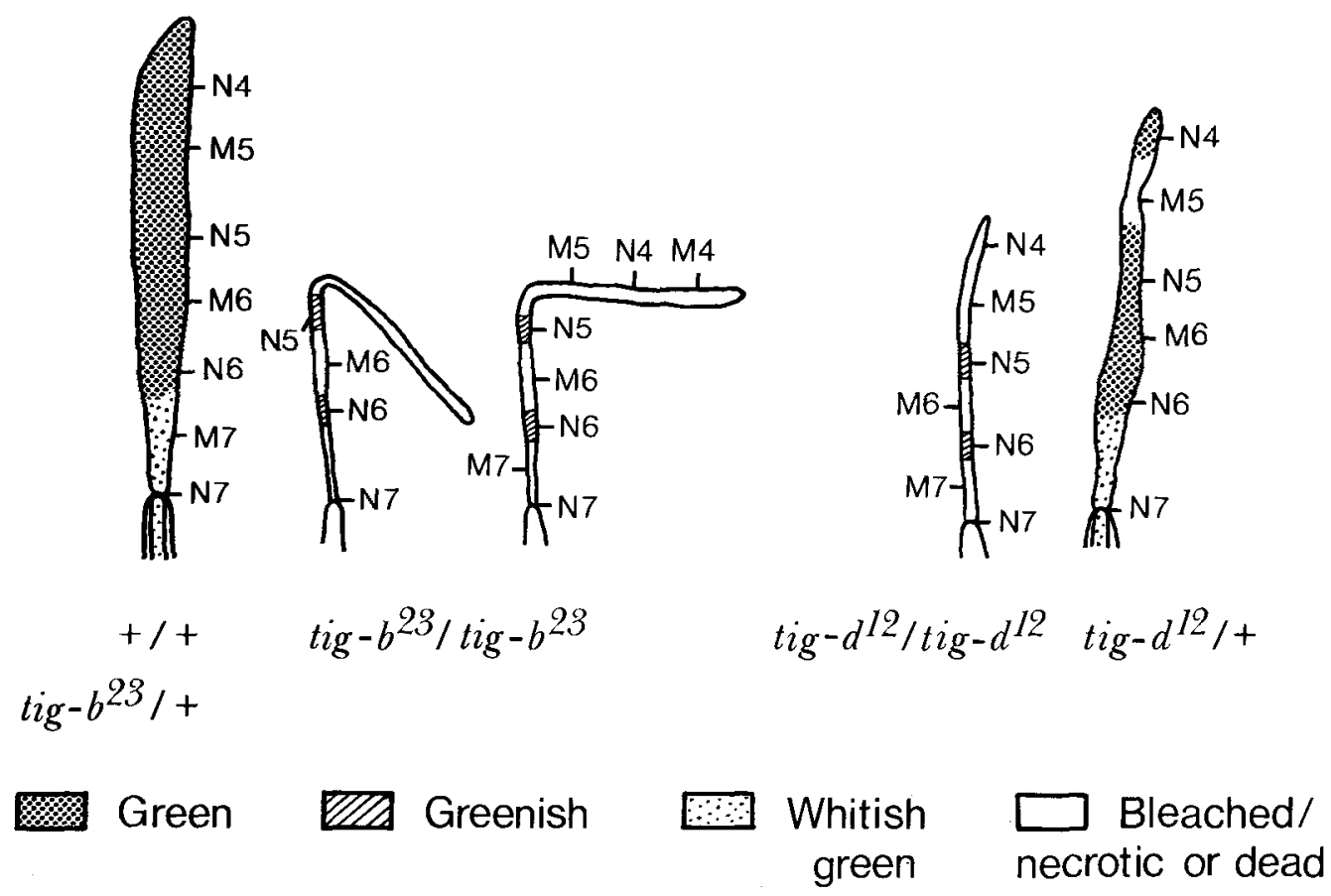

Figure 1. The tigrina phenotype in tig- $d^{12}$ and $t i g \cdot b^{23}$.

Seeds segregating for tig-d $d^{12}$ and tig- $b^{23}$ were sown in a window box. The temperature during the growth period was about $20^{\circ} \mathrm{C}$. During the night the seedlings were covered with a black cloth. The primary leaf with the coleoptile was drawn as it appeared on the evening of the seventh day after sowing. The leaf first emerged through the coleoptile on the fourth day. The leaves were marked just above the coleoptile in the mornings (M) and at night $(\mathrm{N})$ on each day so that the extension growth could be followed. The numbers indicate the age of the plant in days after sowing. The segregation observed under these conditions were: homozygous $t i g-b^{23}, 25 \%$, homozygous tig-dII, $24 \%$, and heterozygous tig- $d^{I 2}$ with expressed necrotic band, $26 \%$. 


\subsection{Determination of total iron in shoots by flame ionisation spectroscopy}

Approx. two g of leaves were incinerated overnight in a crucible and the residue was dissolved in $3 \mathrm{~N} \mathrm{HCl}(4 \mathrm{ml})$. The crucible was washed twice with $10 \mathrm{ml}$ of $3 \mathrm{~N} \mathrm{HCl}$ and the combined extracts was adjusted to $25 \mathrm{ml}$. The iron content of this solution was then determined using a Perkin-Elmer, model 305B atomic absorption spectrometer.

\section{RESULTS AND DISCUSSION}

\subsection{Development of the tigrina phenotype in tig- $d^{12}$ and $t i g-b^{23}$}

The tigrina phenotype has been described as alternating necrotic or bleached and green transverse bands on the leaf. This phenotype is expressed only when the tigrina mutant seedlings are grown in alternating white light and dark cycles $(20,22)$. Since the barley leaf grows primarily by elongation of its basal portion the development of the tigrina phenotype was followed in tig- $d^{I / 2}$ and the $\beta$-carotene deficient (17) tig- $b^{23}$ by marking the leaf just above the coleoptile at the begining and end of each light period during the growth of the leaves. The mark $\mathrm{M}$ was made in the morning at the begining of the light period and the mark $\mathrm{N}$ was made at night at the end of the light period. In Figure 1 the primary leaves including the coleoptiles have been drawn as seen on the evening of the seventh day. The area of the leaf just above and below the marks N4, N5, N6 and N7 correspond to the areas of the leaf where extension growth occurred in the light period of the 4th, 5 th, 6 th and 7th day. The areas of the leaf around the marks M4, M5, M6 and M7 indicate the regions of the leaf where extension growth occurred during the $3 \mathrm{rd}, 4 \mathrm{th}, 5$ th and 6 th night. A green band corresponding to $\mathrm{N} 4$ could not be seen in the top portion of the primary leaf of the tigrina mutants when viewed on the evening of the seventh day. The lack of this band is explained as due to a more acute damage of this region of the leaves. This is most strongly illustrated by the $\beta$-carotene deficient $t i g-b^{2.3}$ mutants all of which had $a$ bend in the leaf below the mark M5 due to advanced necrosis. The tig- $d^{12}$ gene is also particularly active during the 4 th night. This is illustrated by a bleached band corresponding to leaf extension on the 4th night which was observed in $26 \%$ of the seedlings from the tig$d^{12}$ seed material. These seedlings were otherwise normally green. Such seedlings with a single bleached band have previously been identified as heterozygotes (16). The basal and youngest portion of the leaf in the wild type and heterozygous seedlings is whitish in colour illustrating that chlorophyll and carotenoid synthesis have just begun. It is concluded that the bleached or necrotic bands observed in the tigrina phenotype are due to damage caused a photosensitising pigment which accumulates during the dark but not in the light during leaf extension growth. The mutants $t i g-b^{23}, t i g-o^{34}$, tig- $n^{32}$ and $t i g-n^{33}$ have a defective $\beta$-carotene biosynthesis (17) which may make them more sensitive to light. In contrast to $t i g-d^{12}$ these mutants are not viable in continuous light. Since the tigrina mutants tig- $d^{\prime 2}$, tig- $0^{34}$ and alleles at the tig- $b$ and tig- $n$ loci accumulate more protochlorophyllide in the dark than the wild type, this pigment could be the photosensitiser responsible for the photodamage.

\section{2. $\delta$-aminolevulinate formation in tigrina mutants}

\subsubsection{D-aminolevulinate formation in tigrina mutants in the dark}

In Figure 2 the rates of $\delta$-aminolevulinate accumulation in tigrina mutants and wild type barley at various ages in the dark are compared with the levels of protochlorophyllide present. Two kinds of wild type seedlings served as control material for comparison with the tigrinas. One was the phenotypic wild type seedlings in the segregating progenies which included heterozygotes in addition to the homozygous wild type. The other was Bonus barley being homozygous for the wild type allele. In this manner effects of the tigrina genes in the heterozygous condition on $\delta$-aminolevulinate formation could be assessed. The tig- $0^{34}$ lesion results in a partial metabolic block in the conversion of lycopene to $\beta$-carotene (17). In the experiment shown in Figure 2, tig- $0^{34}$ mutants could not be distinguished from the wild type on the 4 th, 5 th or the 6 th day because the mutants had not yet developed sufficient protochlorophyllide to distinguish them from the wild type. It is 


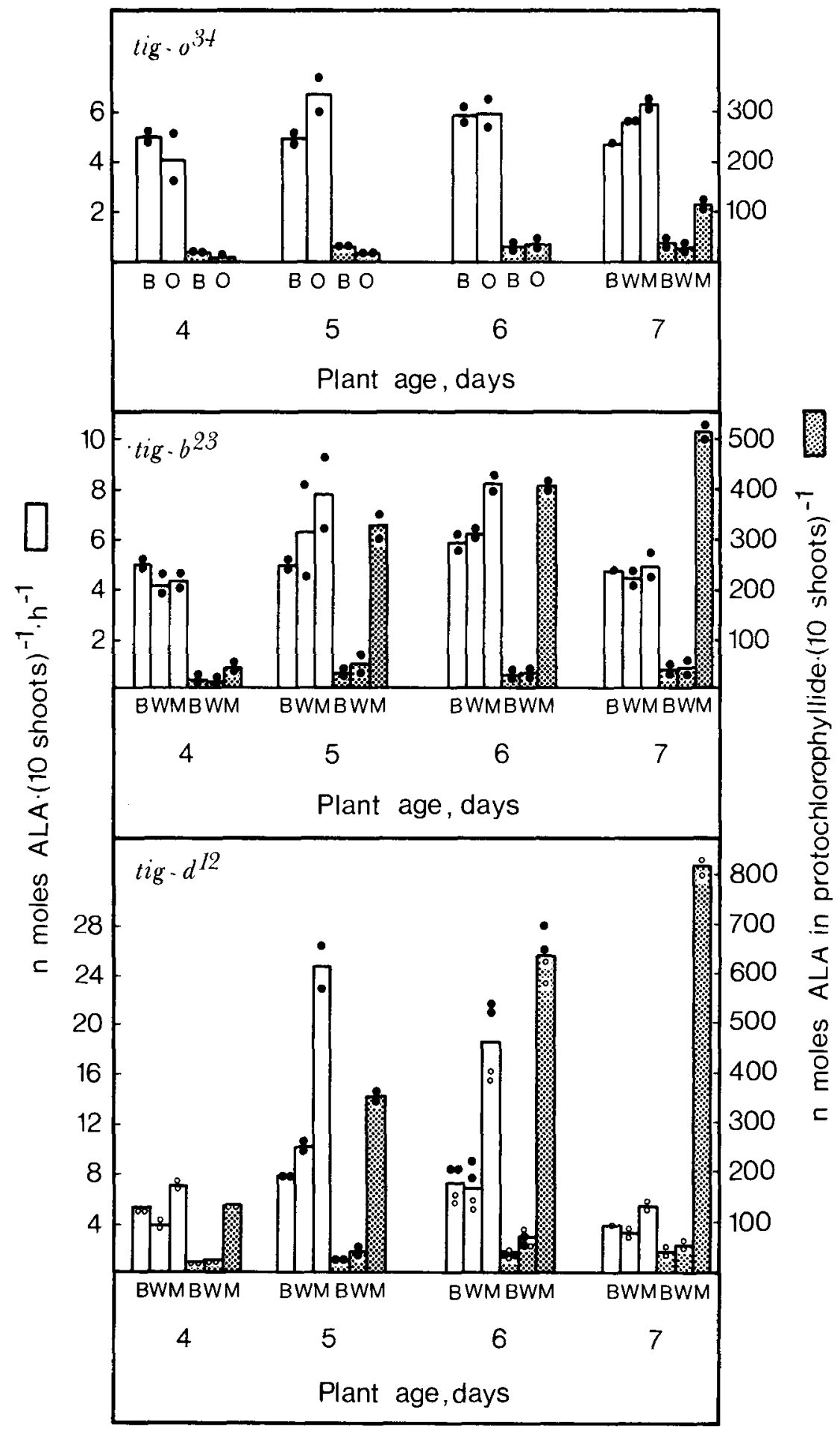


Figure 2. The rates of $\delta$-aminolevulinate accumulation in the presence of levulinate in tigrina-o $o^{34}$, tigrina- $b^{23}$ and tigrina-d/2.

Plants were grown for 4, 5, 6 and 7 days in the dark at $25^{\circ} \mathrm{C}$. Approximately uniform size shoots were harvested and infiltrated with $20 \mathrm{~mm}-\mathrm{Na}$ levulinate, $\mathrm{pH}$ 6.5. The shoots were then placed in the dark at $25^{\circ} \mathrm{C}$ for five hours with their cut ends immersed in the levulinate solution. At the end of this treatment the shoots were cooled and mutant and wild type shoots were identified in dim white light. Dark levels of protochlorophyllide were obtained by summation of the protochlorophyllide and chlorophyll formed during the exposure to dim light. Abbreviations: B, wild type (Bonus) control; W, phenotypic wild type seedlings (containing heterozygotes); $\mathrm{M}$, homozygous mutants; $\mathrm{O}$, phenotypic wild type seedlings plus homozygous mutants. The samples were analysed in duplicate and for $t i g-d / 2$ data from two separate experiments are given. known that this mutant tends to become normalised at growth temperatures above $20^{\circ} \mathrm{C}$ (16). For the seedlings on these days data are therefore given for the unsorted material. On the 4th and 5th day the protochlorophyllide content is less than that of the Bonus control. When the tig-o $o^{34}$ mutants became identifiable by their higher protochlorophyllide content on the 7 th day it was observed that they had an increased rate of $\delta$-aminolevulinate accumulation compared to the wild type Bonus.

The rates of $\delta$-aminolevulinate accumulation in tig- $d^{\prime 2}$ was higher than that in the two kinds of wild type controls at all ages tested. On the 5 th day the rate of $\delta$-aminolevulinate accumulation in tig- $d^{I 2}$ was highest when it was 3-fold that seen in the Bonus control. The phenotypic wild type seedlings which included tig- $d^{12}$ heterozygotes also showed higher rates on the 5 th day compared to the Bonus control indicating that

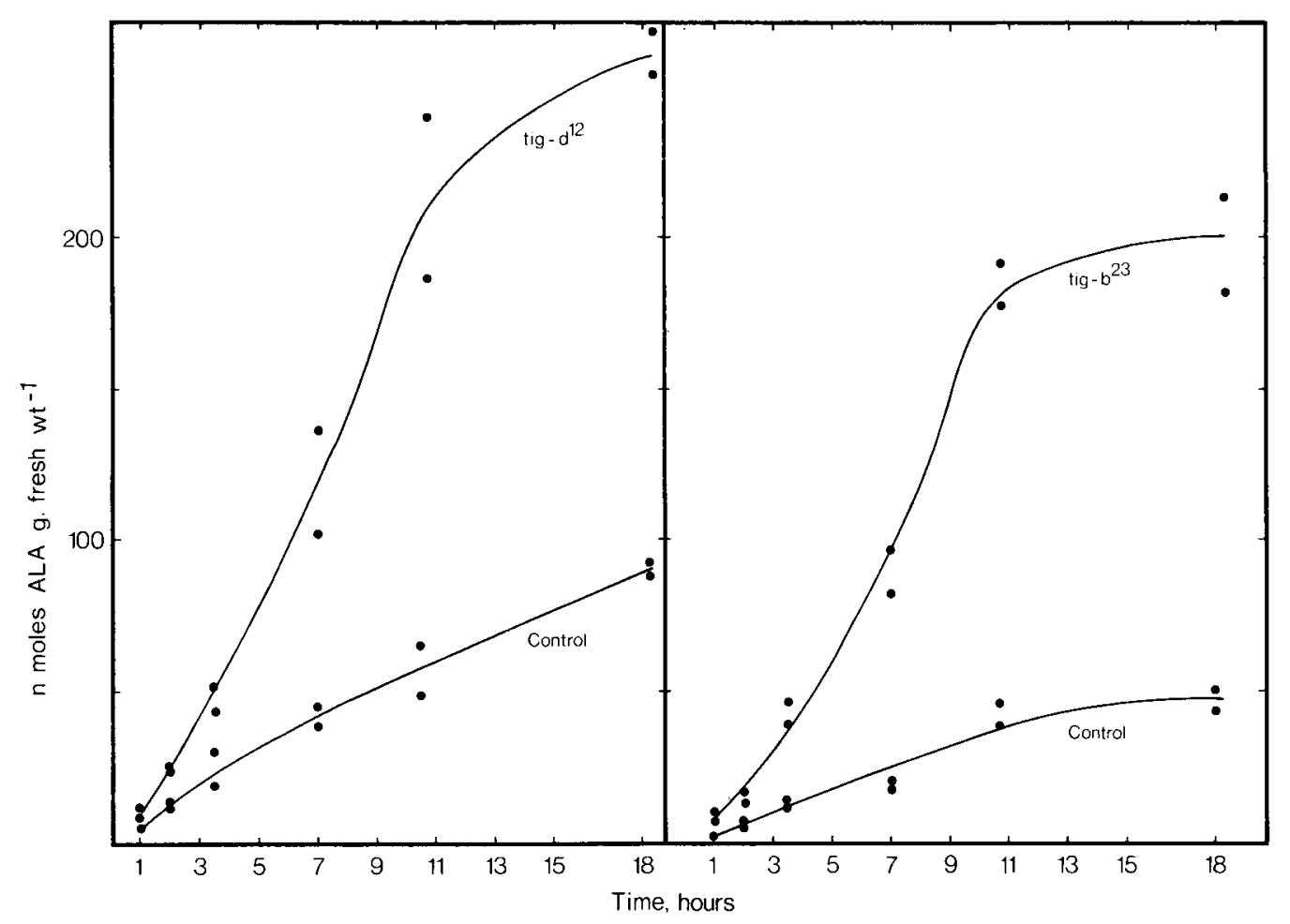

Figure 3. $\delta$-Aminolevulinate accumulation in $t i g-d^{2}$ and $t i g-b^{23}$ with increasing periods of levulinate feeding.

Seedlings were grown in the dark for five days at $21^{\circ} \mathrm{C}$. The shoots were cut and placed in the dark with their cut ends immersed in a $20 \mathrm{~mm}-\mathrm{Na}$-levulinate solution at $\mathrm{pH}$ 6.5. Air was moved over the leaves with a fan. At different periods of time indicate batches of shoots were cooled on ice and mutants were sorted and the $\delta$ aminolevulinate formed was extracted, purified and the pyrrole derivative chromatographed on thin plates before determination. 
the $t i g-d^{12}$ gene in heterozygous condition affects the regulation of $\delta$-aminolevulinate formation. The rates of $\delta$-aminolevulinate accumulation in tig- $d^{12}$ increased from the 4 th to the 5 th day and decreased thereafter. Protochlorophyllide accumulated from the 4th to the 7 th day and it is apparent that rapid protochlorophyllide synthesis occurs in 5 day old seedlings indicating a positive correlation between the rate of $\delta$ aminolevulinate formation and protochlorophyllide synthesis in $t^{i g}-d^{12}$.

In the $t i g-b^{23}$ mutant which has a defective conversion of $\varsigma$-carotene to $\beta$-carotene (17), the rate of $\delta$-aminolevulinate accumulation on the 5 th day was 1.6-fold that in the Bonus control. The rate of $\delta$-aminolevulinate accumulation in $t i g-b^{23}$ remained elevated on the 6th day and decreased thereafter. Protochlorophyllide accumulation in tig- $b^{23}$ occurred most rapidly between the 4th and the 6th day and is correlated with the increased rates of $\delta$-aminolevulinate accumulation observed on the 5 th and 6 th days.

The time course of $\delta$-aminolevulinate accumulation in excised leaves of 5 day old tig- $d^{22}$ and the $\beta$-carotene deficient $t i g \cdot b^{23}$ in the dark is given in Figure 3. The mutant leaves accumulated more $\delta$-aminolevulinate than the wild type controls with time when fed with levulinate. The rates of $\delta$-aminolevulinate formation calculated from the data in Figure 3 for the wild type control was 4 to 6 nmoles $\delta$-aminolevulinate.g fresh weight ${ }^{-1}$.hour ${ }^{-1}$ up to 8 hours of incubation. The mutants accumulated $\delta$-aminolevulinate at a rate of 15 to 18 nmoles.g fresh weight $^{-1}$.hour ${ }^{-1}$ at the 4 th hour increasing to 25 to 27 nmoles-g fresh weight ${ }^{-1}$.hour ${ }^{-1}$ at the 8 th hour on levulinate. Thus the mutants have a rate of $\delta$-aminolevulinate accumulation 3 to 6 -fold that of the wild type. In both the wild type and the mutants the $\delta$-aminolevulinate accumulation leveled off after 8 hours. It is concluded that the overproduction of protochlorophyllide in $t i g-d^{12}$, in mutants at the $t i g-b$ locus and in tig- $o^{34}$ is due to an unregulated formation of $\delta$-aminolevulinate in the dark.

It has been shown that iron chelators stimulate protochlorophyllide and $\delta$-aminolevulinate formation in etiolated beans (4) and barley (GougH unpublished). The total iron content of leaves of $t i g-b^{23}, t i g-d^{12}$ and $t i g-o^{34}$ varied from $5 \mu \mathrm{g} \cdot \mathrm{g}$ fresh weight ${ }^{-1}$ to $7 \mu \mathrm{g} \cdot \mathrm{g}$ fresh weight ${ }^{-1}$ and was not different from that in wild type controls. Therefore the overproduction of protochlorophyllide and increased rates of $\delta$-aminolevulinate synthesis in the tigrina mutants are not due to an iron deficiency.

\subsubsection{The effect of a short illumination on $\delta$ - aminolevulinate accumulation in tigrina mutants}

It has previously been shown that $\delta$-aminolevulinate accumulation in dark grown levulinate treated wild type barley seedlings is stimulated by exposing them to a short light period (8). A short illumination of $t i g-b^{23}$ and $t i g-d^{12}$ inhibited $\delta$-aminolevulinate accumulation by 70 and $100 \%$ respectively, in contrast to wild type where light greatly stimulated the rate of $\delta$ aminolevulinate synthesis (Figure 4). In seedlings heterozygous for $t i g-d^{12}$ and in phenotypic wild type seedlings comprising $2 / 3$ of $+/$ tig $-b^{2.3}$ seedlings and $1 / 3+/+$ seedlings a stimulation of the rate of $\delta$-aminolevulinate synthesis was also observed after a five minute illumination. During this light period, 5 to 8 nmoles of chlorophyll was formed in the wild type and 3 to 4 nmoles of chlorophyll in tig-d $d^{2}$ and $t i g-b^{2 ?}$. A large amount of photoinactive protochlorophyllide was present in the mutants after the illumination. The inhibition of $\delta$-aminolevulinate synthesis in $t i g-b^{23}$ and $t i g-d^{12}$ by light may be due to photodynamic damage caused by the excess of protochlorophyllide present in these mutants. In $t i g-d^{\prime 2}$ a loss of pigment (protochlorophyllide plus chlorophyll) occurred during the illumination but in the wild type controls and in $t i g-b^{23}$ there was no evidence for such a loss.

\subsection{The $\delta$-aminolevulinate synthesising enzyme in tigrina mutants}

\subsubsection{The precursor for $\delta$-aminolevulinate synthesis in tigrina mutants}

In order to determine whether tigrina mutants synthesise the $\delta$-aminolevulinate from glutamate or from succinate and glycine these compounds were fed in ${ }^{14} \mathrm{C}$ labelled form to dark grown mutant leaves. Leaves of $t i g-b^{23}, t i g-d^{12}$ and wild type were fed for four hours with glycine- $2-{ }^{4} \mathrm{C}$, succinate-2, $3{ }^{14} \mathrm{C}$ or glutamate- $1-{ }^{14} \mathrm{C}$ in the dark in the presence of $25 \mathrm{~mm}$-levulinate and 


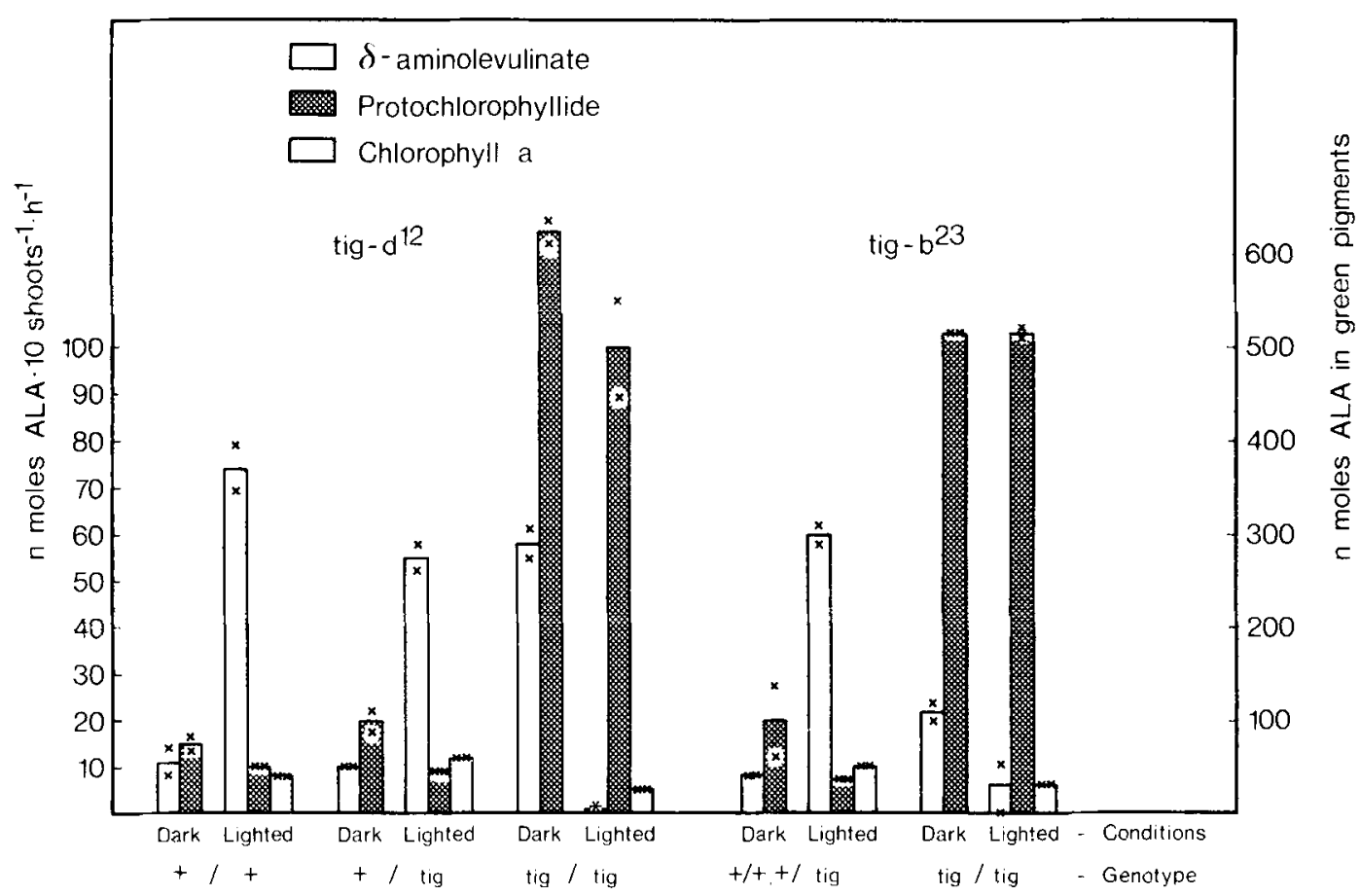

Figure 4. The effect of a brief illumination on $\delta$-aminolevulinate accumulation in $t i g-b^{23}$ and $i g-d^{\prime 2}$.

Leaves from 6 day old dark-grown seedlings were incubated in $20 \mathrm{~mm}-\mathrm{Na}$-levulinate at $\mathrm{pH} 6.5$ for 2 hours. One group of shoots was frozen and another exposed to five minutes of light at $25 \mathrm{ft}$ candles and returned to darkness for one hour. The $\delta$-aminolevulinate was determined without purification. Chlorophyll $a$ and protochlorophyllide were determined in $80 \%$ acetone using for chlorophyll $a \varepsilon_{\mathrm{mm}} 665 \mathrm{~nm} 81.1, \varepsilon_{\mathrm{mm}} 628 \mathrm{~nm}$ 14.7 (19) and for protochlorophyllide $\varepsilon_{\mathrm{mm}} 628 \mathrm{~nm} 34.5(6) .{ }^{*} \delta$-aminolevulinate levels decreased and were actually 6 and 14 nmoles below the dark level.

analysed for radioactivity incorporated into $\delta$ aminolevulinate (Figure $5 \mathrm{~A}$ and Figure $5 \mathrm{~B}$ ). Of the three compounds tested succinate-2, $3-{ }^{14} \mathrm{C}$ was most effectively incorporated into $\delta$-aminolevulinate, followed by glutamate- $1-{ }^{14} \mathrm{C}$, whereas glycine $-2 \cdot{ }^{14} \mathrm{C}$ was very poorly incorporated. The radioactivity from glutamate- $1-1^{14} \mathrm{C}$ cannot be incorporated into $\delta$-aminolevulinate via succinate unless the respired ${ }^{14} \mathrm{CO}_{2}$ is refixed. The incorporation of glutamate- $1-{ }^{14} \mathrm{C}$ into $\delta$-aminolevulinate by $t i g-b^{23}$ and $t i g-d^{12}$ and wild type barley in the dark indicates that these leaves biosynthesise $\delta$-aminolevulinate in the dark the five-carbon pathway $(2,12)$. The observation that succinate-2,3-14 $\mathrm{C}$ is incorporated more effectively into $\delta$-aminolevulinate than glutamate $-1-{ }^{4} \mathrm{C}$ is expected if succinate is taken up faster than the two amino acids by etiolated leaves and rapidly converted by the mitochondria into $\alpha$-ketoglutarate and then into glutamate.

\subsubsection{Incorporation of radioactive substrates into $\delta$-aminolevulinate by etioplasts isola- ted from tig-d $d^{12}$ and wild type barley}

The etioplasts isolated from six day old $\mathrm{tig}-\mathrm{d}^{12}$ seedlings incorporated glutamate- $1-{ }^{14} \mathrm{C}$ and $\alpha$ ketoglutarate- $1-{ }^{14} \mathrm{C}$ into $\delta$-aminolevulinate tenfold better than succinate-2,3-14 $\mathrm{C}$ (Table I). With etioplasts from wild type these two substrates were five to three fold better than succinate-2, $3-{ }^{14} \mathrm{C}$. Thus both wild type and tig- $d^{12}$ etioplasts synthesise $\delta$-aminolevulinate by the five-carbon pathway rather than from succinate and glycine. Assuming that the six day old tig- $d^{12}$ shoots contained about 80 nmoles protochlorophyllide and wild type shoots about 8 nmoles of protochlorophyllide per 10 shoots (see Figure 2) the incorporation can be calculated on a per shoot basis (Table I). It is then apparent that tig$d^{2}$ etioplasts incorporate two to three times more radioactivity into $\delta$-aminolevulinate from 


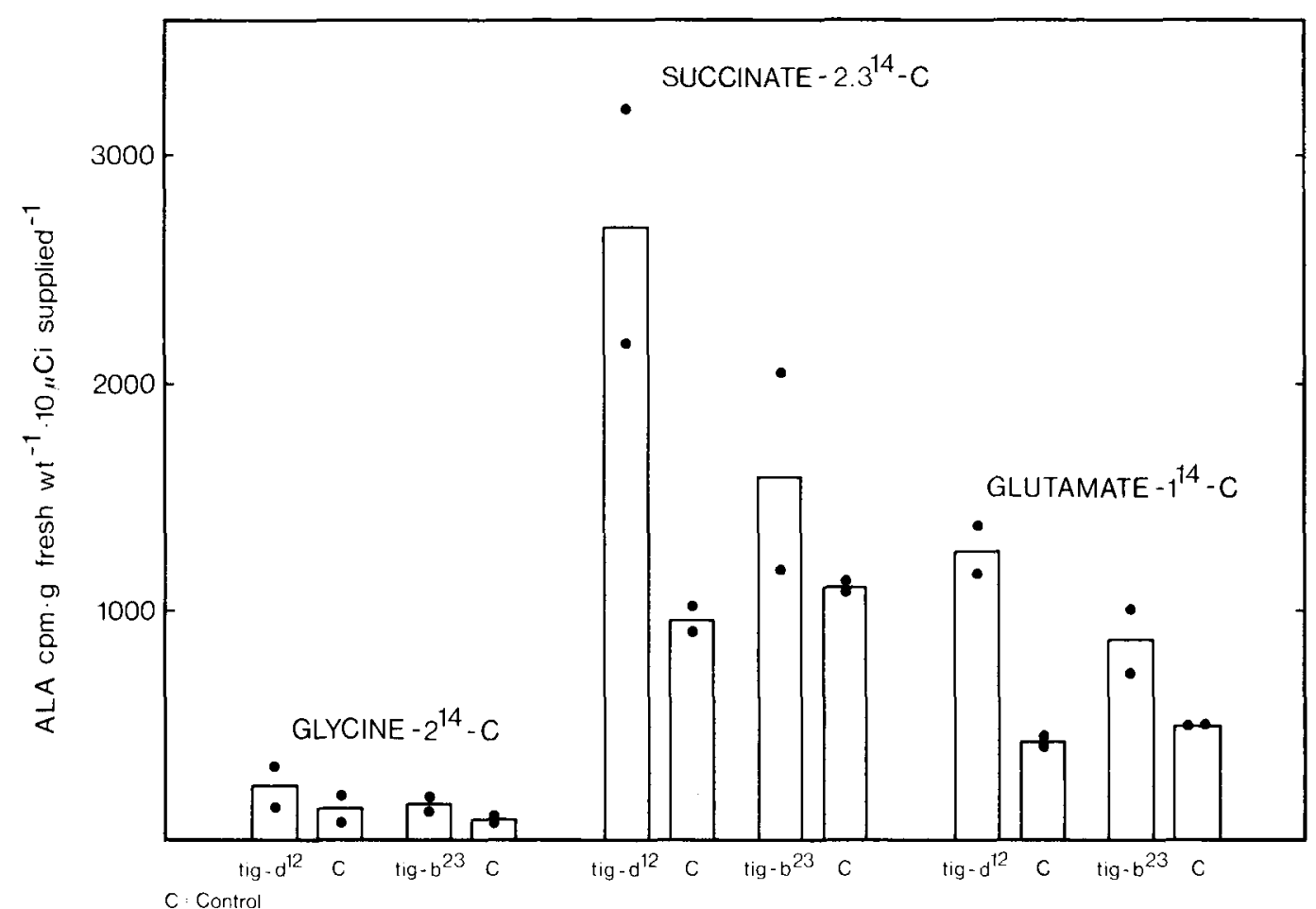

Figure 5A. Radioactivty (cpm) incorporated into $\delta$-aminolevulinate per $\mathrm{g}$ fresh weight of leaves and per $10 \mu \mathrm{Ci}$ supplied.

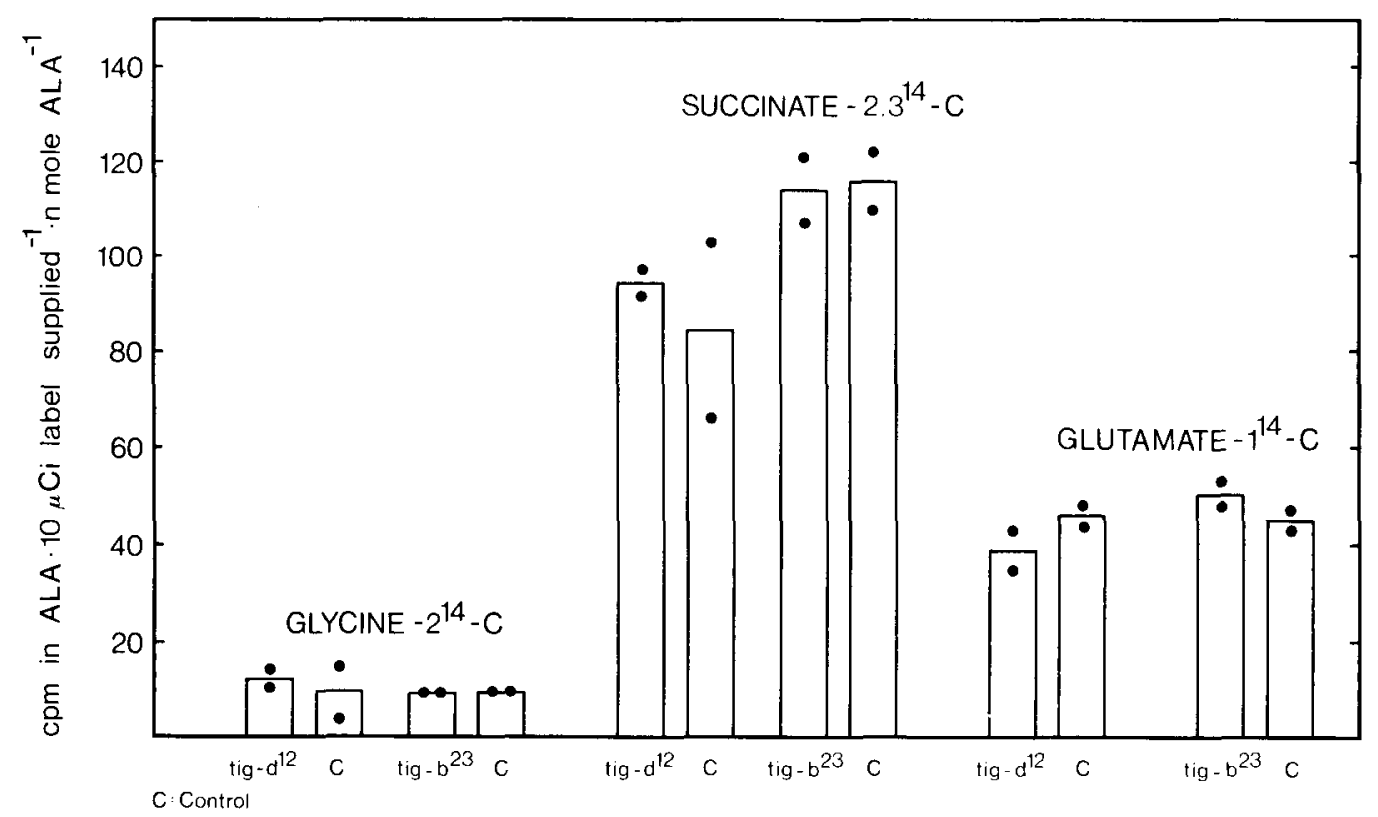

Figure 5B. The specific radioactivity of the $\delta$-aminolevulinate- ${ }^{14} \mathrm{C}$ formed. 
Figure 5. Incorporation of radioactive substrates into $\delta$-aminolevulinate in tigrina mutants in the dark.

Leaves from five day old seedlings grown in the dark at $21^{\circ} \mathrm{C}$ were cut and placed for four hours with their cut ends immersed in two ml solution of $25 \mathrm{~mm}-\mathrm{Na}$-levulinate at $\mathrm{pH} 6.5$ containing the following labelled compounds. L-glutamate- $1-{ }^{14} \mathrm{C} 10 \mu \mathrm{Ci}$, or succinate- $2,3 .{ }^{14} \mathrm{C} 10 \mu \mathrm{Ci}$ or glycine- $2-{ }^{14} \mathrm{C} 20 \mu \mathrm{Ci}$. The $\delta$ aminolevulinate was determined after thin layer chromatography of the pyrrole derivative (see 2.11 ). The incorporation of glycine-2-14 C into $\delta$-aminolevulinate may be somewhat overestimated due to the presence of other radioactive compounds migrating close to the pyrrole derivative of $\delta$-aminolevulinate- ${ }^{4} \mathrm{C}$.

\section{Table 1}

Incorporation of radioactive substrates into $\delta$ aminolevulinate in the dark by etioplasts from $t i g-d^{\prime 2}$ and wild type barley.

The etioplasts were isolated from six day old dark grown shoots using a homogenisation medium containing 3 mM-Ca(NO$)_{2}$ in addition to the components given in 2.6. The incubation mixture contained 9.4 nmoles of protochlorophyllide in the assays with wild type etioplasts and 30.4 nmoles of protochlorophyllide in tig- $^{\prime 2}$ etioplast assays.

\begin{tabular}{|c|c|c|c|}
\hline \multirow{2}{*}{ Etioplasts from } & \multirow{2}{*}{ Substrate } & \multicolumn{2}{|c|}{${ }^{14} \mathrm{C}$ incorporated into $\delta$-aminolevulinate } \\
\hline & & cpm assay ${ }^{-1}$ & $\mathrm{cpm} \cdot 10$ shoots $^{-1}$ \\
\hline \multirow[t]{3}{*}{ Wild type } & I.-glutamate- $1-14 \mathrm{C}$ & 3654 & 2332 \\
\hline & a-ketoglutarate- $1-14 \mathrm{C}$ & 2184 & 1394 \\
\hline & succinate $-2,3-14 \mathrm{C}$ & 665 & 424 \\
\hline \multirow{3}{*}{$\Delta i g-d / 2$} & I-glutamate-1- ${ }^{4} \mathrm{C}$ & 2490 & 4914 \\
\hline & $\alpha$-ketoglutarate- $\mid-14 \mathrm{C}$ & 2573 & 5078 \\
\hline & succinate $-2.3-14 \mathrm{C}$ & 243 & 480 \\
\hline
\end{tabular}

\section{Table II}

The effect of cycloheximide, chloramphenicol and actinomycin $D$ on $\delta$-aminolevulinate accumulation in the presence of levulinate by dark-grown tigrina- $d^{12}$ leaves in the dark.

In experiment 1 plants were grown for six days at $25^{\circ} \mathrm{C}$ (see 2.3). Mutants and seedlings with wild type phenotype were incubated on distilled water, $0.5 \%$ dimethyl sulphoxide (control for actinomycin D) or antibiotics for two hours. After a further four hours incubation on corresponding solutions containing $20 \mathrm{~mm}$ levulinate, $\delta$-aminolevulinate was determined in the leaves without purification. In experiment 2 plants were grown at $21^{\circ} \mathrm{C}$ (see 2.3) for 5 days. Cycloheximide pretreatment of the mutants and wild type (Bonus) controls was for three hours and the leaves were then transferred to corresponding solutions containing $35 \mathrm{~mm}$-levulinate for four hours. The $\delta$-aminolevulinate was purified and determined after chromatography of the pyrrole. Duplicate determinations are given.

\begin{tabular}{|c|c|c|c|c|c|c|c|c|}
\hline & \multicolumn{2}{|c|}{$\begin{array}{c}\text { Experiment } 1 \\
\text { Cycloheximide } \\
100 \mu \mathrm{g} \cdot \mathrm{ml}^{-1}\end{array}$} & \multicolumn{2}{|c|}{$\begin{array}{c}\text { Chloramphenicol } \\
\text { succinate } \\
100 \mu \mathrm{g} \cdot \mathrm{ml}^{-1} \\
\end{array}$} & \multicolumn{2}{|c|}{$\begin{array}{c}\text { Actinomycin D } \\
100 \mu \mathrm{g} \cdot \mathrm{ml}^{-1}\end{array}$} & \multicolumn{2}{|c|}{$\begin{array}{c}\text { Experiment } 2 \\
\text { Cycloheximide } \\
10 \mu \mathrm{g} \cdot \mathrm{ml}^{-1}\end{array}$} \\
\hline \multicolumn{9}{|c|}{ nmoles $\delta$-aminolevulinate $\cdot g$ fresh weight ${ }^{-1}$} \\
\hline tigrina-d/2 & & & & & & & & \\
\hline - inhibitor & 48 & 42 & 36 & 37 & 51 & 46 & 140 & 160 \\
\hline+ inhibitor & 15 & 19 & 25 & 28 & 39 & 50 & 35 & 58 \\
\hline$\%$ inhibition & \multicolumn{2}{|c|}{62} & \multicolumn{2}{|c|}{27} & \multicolumn{2}{|c|}{9} & \multicolumn{2}{|c|}{69} \\
\hline \multicolumn{9}{|l|}{ Wild type } \\
\hline + inhibitor & 13 & 16 & 17 & 19 & 19 & 20 & & 9 \\
\hline \% inhibition & \multicolumn{2}{|c|}{29} & \multicolumn{2}{|c|}{3} & \multicolumn{2}{|c|}{15} & \multicolumn{2}{|c|}{57} \\
\hline
\end{tabular}


$\alpha$-ketoglutarate- $1-{ }^{14} \mathrm{C}$ and glutamate- $1-{ }^{14} \mathrm{C}$ than wild type etioplasts. It is concluded that both wild type and $t i g-d^{\prime 2}$ etioplasts synthesise $\delta$ aminolevulinate from glutamate and that tig- $d^{12}$ etioplasts have higher capacity to synthesise $\delta$ aminolevulinate than wild type etioplasts.

\subsection{The effect of cycloheximide, chloramphenicol and actinomycin D on $\delta$-aminolevulinate accumulation in tigrina- $d^{12}$}

Cycloheximide inhibited $\delta$-aminolevulinate accumulation in the dark in both tig- $d^{12}$ and the wild type (Table II). Chloramphenicol was somewhat inhibitory in tig- $d^{12}$ but not in the wild type whereas actinomycin D had little effect. In experiment 1 the inhibitory effects are underestimated due to a relatively high unspecific colour development with the Ehrlich reagent when determining the small amounts of $\delta$ aminolevulinate accumulated in the wild type. Cycloheximide is known as an inhibitor of protein synthesis on cytoplasmic ribosomes. Thus cytoplasmic protein synthesis is required both to maintain the basal rates of $\delta$-aminolevulinate formation in the wild type, and the unregulated rates in tig- $d^{12}$. Chloramphenicol inhibits protein synthesis on $70 \mathrm{~S}$ chloroplast ribosomes and it appears that this protein synthesis is also required to a certain extent in order to maintain uncontrolled $\delta$-aminolevulinate synthesis in $t i g-d^{12}$. The $\delta$-aminolevulinate formation caused by a brief illumination in dark grown wild type barley does not require protein synthesis on $70 \mathrm{~S}$ chloroplast ribosomes (8). In vitro assays of stroma fractions have demonstrated that neither cycloheximide nor chloramphenicol at $100 \mu \mathrm{g} \cdot \mathrm{ml}^{-1}$ inhibit the $\delta$-aminolevulinate synthesising enzyme.

\subsection{Regulation of the $\delta$-aminolevulinate synthesising enzyme in barley}

Mutants blocked in the formation of $\mathrm{Mg}$ protoporphyrin from protoporphyrin do not accumulate spectrophotometrically detectable amounts of protopophyrin (6). However, double mutants of $t i g-b$ or tig- $o$ with the mutants blocked in $\mathrm{Mg}$-protoporphyrin formation accumulated protoporphyrin (11). On the basis of these biochemical genetic studies and the rapid turn-over of heme (3) it was suggested that protoporphyrin or heme regulate the activity of the $\delta$-aminolevulinate forming enzyme of barley. It was not possible to demonstrate significant inhibitory effects of protoporphyrin or heme using isolated plastids (7). It was suspected that these compounds failed to penetrate the intact plastids. Since a partially purified $\delta$-aminolevulinate synthesising enzyme from barley is now available (12) the effects of protoporphyrin and heme were tested directly on the enzyme (Table III). Heme at concentrations of $5 \mu \mathrm{M}$ and $50 \mu \mathrm{M}$ inhibited the $\delta$-aminolevulinate synthesising enzyme by 80 and $98 \%$ respectively. Protoporphyrin at $5 \mu \mathrm{M}$ inhibited $\delta$-aminolevulinate formation by $27 \%$ and at $50 \mu \mathrm{m}$ by $90 \%$. Thus heme is a more effective feed back inhibitor of the

\section{Table III}

The inhibition of the $\delta$-aminolevulinate synthesising enzyme by heme and protoporphyrin IX.

Heme and protoporphyrin IX were dissolved in $0.01 \mathrm{M}-\mathrm{KOH}$ : ethanol $(1: 1, \mathrm{v} / \mathrm{v})$ and from a $0.5 \mathrm{~mm}-\mathrm{solution}$ 10 and $100 \mu l$ were added to the incubation mixture. The incubations were carried out in the dark.

\begin{tabular}{|c|c|}
\hline Experiment & $\begin{array}{l}\text { L-glutamate-U- }{ }^{14} \mathrm{C} \text { into } \\
\delta \text {-aminolevulinate (cpm) }\end{array}$ \\
\hline Control & 8561 \\
\hline $\mathrm{KOH} /$ ethanol $10 \mu \mathrm{l}$ & 12118 \\
\hline$+5 \mu \mathrm{M}$ heme & 2616 \\
\hline$+5 \mu \mathrm{M}$ protoporphyrin IX & 8908 \\
\hline $\mathrm{KOH} / \mathrm{ethanol} 100 \mu \mathrm{l}$ & 9635 \\
\hline$+50 \mu \mathrm{M}$ heme & 209 \\
\hline$+50 \mu \mathrm{M}$ protoporphyrin IX & 1047 \\
\hline
\end{tabular}




\section{Table IV}

The light stimulation of $d$-aminolevulinate synthesising activity in disrupted etioplast preparations of wild type.

Plastids were isolated from six days old dark grown barley leaves either in $0.6 \mathrm{~m}$-sucrose, $0.1 \mathrm{M}$-Tricine$\mathrm{NaOH}$ pH 7.9 or $0.6 \mathrm{~m}$-glycerol, $0.1 \mathrm{M}$-Tricine- $\mathrm{NaOH}$ pH 7.9. The plastid pellets obtained in the sucrose medium were suspended in $0.3 \mathrm{M}$-sucrose and the pellets from glycerol medium were suspended in either $0.3 \mathrm{M}$ glycerol or $1.2 \%$ saponin in $0.3 \mathrm{M}$-glycerol. All the plastid suspension media contained in addition $0.1 \mathrm{M}-$ Tricine- $\mathrm{NaOH} \mathrm{pH} 7.9,1 \mathrm{~mm}$-dithiothreitol and $1 \mathrm{mM}-\mathrm{MgCl}_{2}$. These plastids were disrupted as given in 2.7 and assayed as in 2.8.2.

\begin{tabular}{|c|c|c|c|c|c|}
\hline \multirow{2}{*}{$\begin{array}{l}\text { Suspension } \\
\text { medium }\end{array}$} & \multirow{2}{*}{$\begin{array}{l}\text { Incubation } \\
\text { in }\end{array}$} & \multirow{2}{*}{$\begin{array}{l}\text { Protochlorophyllide } \\
\text { nmoles assay }{ }^{-1}\end{array}$} & \multirow{2}{*}{$\begin{array}{l}\text { Photoconversion } \\
\text { per cent }\end{array}$} & \multicolumn{2}{|c|}{$\begin{array}{l}\text { L-glutamate-U- }{ }^{14} \mathrm{C} \text { into } \\
\delta \text {-aminolevulinate }\end{array}$} \\
\hline & & & & cpm assay $^{-1}$ & $\begin{array}{c}\mathrm{cpm} \cdot 50 \text { nmoles } \\
\text { protochloro- } \\
\text { phyllide- }\end{array}$ \\
\hline Sucrose & light & 44 & 96 & 15.215 & 17.290 \\
\hline- & dark & 44 & - & 9.399 & 10.680 \\
\hline Glycerol & light & 48 & 98 & 9.903 & 10.315 \\
\hline- & dark & 48 & - & 4.716 & 4.912 \\
\hline $\begin{array}{l}1.2 \% \text { Saponin } \\
\text { in glycerol }\end{array}$ & $\begin{array}{l}\text { light } \\
\text { dark }\end{array}$ & $\begin{array}{l}36 \\
36\end{array}$ & 60 & $\begin{array}{l}4.854 \\
2.555\end{array}$ & $\begin{array}{l}6.742 \\
3.549\end{array}$ \\
\hline
\end{tabular}

barley $\delta$-aminolevulinate synthesising enzyme than protoporphyrin.

Inhibition of $\delta$-aminolevulinate formation in dark grown leaves is released when protochlorophyllide is converted to chlorophyllide by light. The nature of the release mechanism was studied by testing the effect of light on $\delta$ aminolevulinate synthesising activity in disrupted etioplast preparations which contain active protochlorophyllide holochrome. When etioplast were disrupted in sucrose, glycerol or glycerol plus $1.2 \%$ saponin containing media the $\delta$ aminolevulinate synthesising activities in the preparations were higher in the light than in the dark (Table IV). Light stimulated $\delta$-aminolevulinate synthesis 1.6, 2.1 and 1.9 fold respectively in etioplasts disrupted in sucrose, glycerol and saponin-glycerol media. The protochlorophyllide in the preparations was converted into chlorophyllide in the assays carried out in the light. Photoconversion was almost complete in the sucrose and glycerol media but only $60 \%$ photoconversion was obtained in the saponinglycerol medium. The saponin-glycerol medium has been used to solubilise protochlorophyllide holochrome in barley from the membranes (10). The etioplasts disrupted in this medium gave the lowest $\delta$-aminolevulinate synthesising activity in the dark as well as in the light. Doubling of the activity of the $\delta$-aminolevulinate synthesising enzyme by light demonstrates that the disrupted etioplast preparations contain a photosensitive effector of this enzyme. The observed in vitro activation of the enzyme will permit the identification of the effector and allow an approach to the question of whether protochlorophyllide holochrome or chlorophyllide holochrome is involved.

It was concluded in earlier studies (13, 14) that light stimulation of $\delta$-aminolevulinate formation in vivo was due to provision of adenosine triphosphate and reduced nicotine adenine dinucleotide phosphate and with time to synthesis of the $\delta$-aminolevulinate synthesising enzyme. In this paper it is shown that light also stimulates the activity of the enzyme in disrupted etioplast preparations in which cytoplasmic protein synthesis and light driven cofactor production are eliminated. This direct stimulatory effect of light explains how plants shift from a low rate of $\delta$ aminolevulinate formation in the dark to an immediate high rate of $\delta$-aminolevulinate formation (and chlorophyll generation) when placed into light. 


\section{ACKNOWLEDGEMENTS}

The authors are most grateful to Ms NiNA RASMUSSEN for drawing the figures and Ms LENA KoNGSRUD for typing the manuscript. We thank professor DiTER voN WeTrSTEIN for his help and criticism. A part of this work was carried out at Dr. Sam Granick's laboratory at Rockefeller University by one of the authors (SPG).

\section{REFERENCES}

1. Axelson, L.: In vivo measurement of the photooxidation of chlorophyll pigments in dark grown wheat leaves after treatment with $\delta$-aminolevulinic acid. Physiol. Plant. 31, 77-85 (1974)

2. Beale, S. I., S. P. Gough. \& S. Granick: Biosynthesis of $\delta$-aminolevulinic acid from the intact carbon skeleton of glutamic acid in greening barley. Proc. Nat. Acad. Sci. USA 72, 2719-2723 (1975)

3. Castelfranco, P. A. \& O. T. G. Jones: Protoheme turnover and chlorophyll synthesis in greening barley leaves. Plant Physiol. 55, 485490 (1975)

4. Duggan, J. \& M. Gassman: Induction of porphyrin synthesis in etiolated bean leaves by chelators of iron. Plant Physiol. 53, 206-215 (1974)

5. Foster, R. J., G. C. Gibbons, S. Gough, K. W. Henningsen, A. Kahn, O. F. Nielsen \& D. von Wettstein: Protochlorophyllide holochrome. In: Proceedings of the first European Biophysics Congress. E. Broda et al. eds., Vienese Academy of Medicine, Vienna, vol. 4, pp. 134-149 (1971)

6. Gough, S. P.: Defective synthesis of porphyrins in barley plastids caused by mutation in nuclear genes. Biochim. Biophys. Acta 286, 36-54 (1972)

7. Gough, S. P. \& C. G. Kannangara: Synthesis of $\delta$-aminolevulinate by isolated plastids. Carlsberg Res. Commun. 41, 183-190 (1976)

8. Gough, S. P.: Light stimulated $\delta$-aminolevulinate accumulation in levulinate treated barley seedlings. Carlsberg Res. Commun. 43, 497508 (1978)

9. Granick, S.: Magnesium porphyrins formed by barley seedlings treated with $\delta$-aminolevulinic acid. Plant Physiol. 34, xviii (1959)

10. Henningsen, K. W. \& A. Kahn: Photoactive subunits of protochlorophyll(ide) holochrome. Plant Physiol. 47, 685-690 (1971)
11. Kahn, A., N. Avivi-Bleiser \& D. von WettsTEIN: Genetic regulation of chlorophyll synthesis analysed with double mutants in barley. In: Genetics and biogenesis of chloroplasts and mitochondria. Th. Bücher et al. eds., Elsevier/ North Holland, Amsterdam pp. 119-131 (1976)

12. Kannangara, C. G., S. P. Gough \& D. von WetTSTEIN: Biosynthesis of $\delta$-aminolevulinate and chlorophyll and its genetic regulation. In: Development in Plant Biology 2. Chloroplast Development. G. Akoyunoglou \& J. H. Argyroudi-Akoyunoglou eds., Elsevier/North Holland, Amsterdam, pp. 147-160 (1978)

13. Kannangara, C. G. \& S. P. Gough: Synthesis of $\delta$-aminolevulinate and chlorophyll by isolated chloroplasts. Carlsberg Res. Commun. 42, 441457 (1977)

14. Kannangara, C. G. \& S. P. Gough: Biosynthesis of $\delta$-aminolevulinate in greening barley leaves II: Induction of enzyme synthesis by light. Carlsberg Res. Commun. 44, 11-20 (1979)

15. Nadler, K. \& S. Granick: Controls on chlorophyll synthesis in barley. Plant Physiol. 46, 240-246 (1970)

16. Nielsen, O. F.: Macromolecular physiology of plastids XII. Tigrina mutants in barley: Genetic, spectroscopic and structural characterisation. Hereditas 76, 279-304 (1974)

17. Nielsen, O. F. \& S. P. Gough: Macromolecular physiology of plastids XI. Carotenes in etiolated tigrina and xantha mutants of barley. Physiol. Plant 30, 246-254 (1974)

18. Stumann, B. M.: Tetrapyrrole protein complexes from wild type barley and barley mutants affecting chlorophyll synthesis. Biochem. Physiol. Pflanzen 173, 249-269 (1978)

19. Vernon, L. P.: Spectroscopic determination of chlorophylls and pheophytins in plant extracts. Anal. Chem. 32, 1144-1150 (1960)

20. Wettstein, D. von \& K. Kristensen: Stocklist for nuclear genes affecting the chloroplast. Barley Genetics Newsletter 3, 11 3-117 (1973)

21. Wettstein, D. von, A. Kahn, O. F. Nielsen \& S. GougH: Genetic regulation of chlorophyll synthesis analysed with mutants of barley. Science 184, 800-802 (1974)

22. Wettstein, D. von: Genetic regulation of membrane synthesis in chloroplasts as studied with lethal gene mutants. In: Membranes and Disease. L. Bolis et al. eds., Raven Press, New York, pp. 123-130 (1976) 